\title{
For Decision-Making in Family Medicine Context is the Final Arbiter
}

\author{
Jose Luis Turabian* \\ Health Center Santa Maria de Benquerencia Toledo, Spain
}

*Corresponding author: Jose Luis Turabian. Health Center Santa Maria de Benquerencia Toledo, Spain, Tel: 34925154508; E-mail: jturabianf@hotmail.com

Received date: July 03, 2017; Accepted date: July 03, 2017; Published date: July 10, 2017

Copyright: @ 2017 Turabian JL. This is an open access article distributed under the terms of the Creative Commons Attribution License, which permits unrestricted use, distribution, and reproduction in any medium, provided the original author and source are credited

\begin{abstract}
There is a lack of knowledge about the diagnostic process in medical experts, and there is no clear consensus regarding its systematization in practice, teaching and evaluation. For the medical expert, clinical reasoning has become an ingrained form of thinking and is done "without realizing". The diagnostic process is a mental operation through which pathology is identified and the disease is evaluated. But the diagnosis is made by medical expert in a similar way as of the painter when he manages to highlight a figure on a background, when recognizing the edges by contrast, and so, only by observing colour in its context can you begin to understand its nature. For the family doctor, the same problem takes different forms according to its background. There are different diagnoses of the same symptom according to contexts. The professional intuition is sometimes marvellous and sometimes flawed. To map the boundary conditions that separate true intuitive skill from overconfident and biased impressions it should be based in the contextual evidence. The way to arrive at objective decisions is to contextualize. The complexity of family medicine lies in the contextualization of medical care in each patient.
\end{abstract}

Keywords: Diagnosis; Family practice; Qualitative analysis; Clinical competence; Context

\section{Editorial}

Clinical reasoning is an example of the scientific method and is fundamental for the practice of family medicine. The analysis of how diagnoses are made is currently influenced by statistical models and information from large databases of electronic medical records [1]. Although during the last decades it has been a research topic and much has been learned, however, there is still a lack of knowledge about the diagnostic process in medical experts, and there is no clear consensus regarding its systematization in practice, teaching and evaluation [2]. In addition, clinical reasoning is difficult to teach and learn. The integration between scientific information, the patient's personal circumstances and non-clinical parameters constitute what has traditionally been termed "the art of medicine" [3].

"In the arid landscape the sky is the final arbiter"

Paul Bowles. Their Heads are Green and their Hands are Blue.

For the medical expert, clinical reasoning has become an ingrained form of thinking and is done "without realizing", and he or she may have difficulty explaining it. Thus, students may find it difficult to understand, because in fact it is invisible and inaccessible to them. Clinical decision making can be described as the answering to the question: "What is the best thing for this patient at this time?" In addition to incorporating clinical information, research evidence, and patient preferences, the process requires considering contextual factors that are unique of each patient and relevant to their care [4]. Making a clinical decision in the treatment of a specific patient requires information on the clinical profile of the patient [5]. The family doctor sees a patient in ten minutes, during which time a diagnosis is made and treatment is performed. For a novice observer, such as a medical student or a resident, this is incomprehensible, it's magic! It's like pulling a rabbit out of the hat. So, we need to know the trick if we want to be able to repeat it. How does the family doctor make these diagnoses appear or disappear and how does he guess the thoughts of the patient? The meaning of "art" or "clinical expertise" is associated with the ability to manage the uncertainty of the problem. Trying to negate the "old" concept of "clinical eye of the wise physician" (subjective) to emphasize clinical epidemiology (objective) as the unique approach is a mistake in the development of the family doctor.

The clinical emerges, that is, it is perceived by the clinician within a theoretical framework that clarifies the reality. From that moment, there are a number of clinical strategies to manage the uncertainty of decision-making: the internal consistency of the doctor, congruence with other stakeholders, the internal consistency of semiotics, and temporal consistency. Each of these strategies has a number of clinical techniques. From the paradigm of positivist science (quantitative, objective) the clinician primarily uses clinical epidemiology and evidence based medicine strategies to manage uncertainty. But many other techniques are more frequently used. These techniques are the "tricks of the magician" and they are qualitative techniques [6,7]. The diagnostic process is a mental operation through which pathology is identified and the disease is evaluated. The complexity of family medicine lies in the contextualization of medical care in each patient [8-11]. The family doctor works in an environment in which there is a high prevalence of symptoms of malaise, but a low prevalence of established disease and the disease episode is a part of the totality of a landscape [11-13]. The diagnosis is made by a mechanism similar to that of the painter when he manages to highlight a figure on a background: "when recognizing the edges by contrast" [14]. Thus, the same problem takes different forms according to its background; different diagnoses according to contexts. This can be difficult to understand.

Only by observing "colour in its context" can the painter and the family doctor begin to understand the nature/the symptoms. From here it could be conclude that colour is "unstable, and susceptible to change" depending on its proximity to other colours. Therefore, there is not a valid formula for interpretation of the meaning of symptoms ant the diagnostic. A "colour" can acquire two different faces. The more different the background colour is, the greater the influence on the colour placed inside. Likewise, two completely different colours may look like the same colour when interacting with the colours alongside them. For the family doctor the diagnosis is made using a similar mechanism. The diagnosis is intended to highlight a picture on a background, "to recognize the contrast edges". Thus, the same problem 
Citation: Turabian JL (2017) For Decision-Making in Family Medicine Context is the Final Arbiter. J Gen Pract (Los Angel) 5: e117. doi:

Page 2 of 2

takes different forms depending on the background-different diagnoses according to different contexts. Through to stand out a picture on a background ("contextualize"). For the family doctor, it can be seen that same health problem causes completely different effects depending on the environment (personal, family, work, community, and context). The family doctor has to put the symptom in context. The symptom "depends" (and they should be valued) on its environment. The professional intuition is sometimes marvellous and sometimes flawed. To map the boundary conditions that separate true intuitive skill from overconfident and biased impressions it should be based in the contextual evidence. The way to arrive at objective decisions is to contextualize [15]. For decision-making in family medicine context is the final arbiter.

\section{References}

1. Gottlieb A, Stein GY, RuppinE, Altman RB, Sharan R (2013) A method for inferring medical diagnoses from patient similarities. BMC Medicine, 11: 194.

2. Durnin S, Artino AR, Schuwirth L, van der Vleuten C (2013) Clarifying assumptions to enhance our understanding and assessment of clinical reasoning. Acad Med 88: 442-448.

3. Hajjaj FM, Salek MS, Basra MKA, Finlay AY (2010) Non-clinical influences on clinical decision-making: A major challenge to evidence-based practice. J R Soc Med 103: 178-187.

4. Weiner SJ (2004) Contextualizing medical decisions to individualize care. Lessons from the qualitative sciences. J Gen Intern Med 19: 281-285.
5. Aro AR, Smith J, Dekker J (2008) Contextual evidence in clinical medicine and health promotion. Eur J Public Health 18: 548-549.

6. Turabián JL, Franco PB (2005) A way to make clinical pragmatism operative: Systematization of the actuation of competent physicians. Med Clin (Bar) 124: 476.

7. Turabian JL, Franco PB (2016) The family doctors: Images and metaphors of the family doctor to learn family medicine. Nova Publishers, New York.

8. Turabián JL, Ocampo SE, Minier L, Franco PB (2015) Learning concepts of diagnosis in family medicine: The "mark robinson sign", the traces that should not be there. Aten Primaria 47: 596-602.

9. Turabian JL, Franco BP (2017) Responses to clinical questions: Specialistbased medicine vs. reasonable clinic in family medicine. Integr J Glob Health 1: 1 .

10. Turabian JL, Franco PB (2010) An easy or difficult case? Shapes drawn from life. Uncertainty based family medicine. Semergen 36: 485-490.

11. Turabian JL, Franco PB (2010) The diagnostic concept in family medicine: A view of the landscape. The diagnosis in family medicine. Aten Primaria 42: 66-69.

12. Heath I, Evans P, Weel CV (2000) The specialist of the discipline of general practice. BMJ 320: 326-327.

13. McWhinney IR (1996) The importance of being different. Br J Gen Pract 46: 433-436.

14. Turabian JL, Franco PB (2008) Individual health care with community orientation - Context care: the figure is the background. Revista Clínica Electrónica en Atención Primaria.

15. Wilson HJ (2000) The myth of objectivity: Is medicine moving towards a social constructivist medical paradigm? Fam Pract 17: 203-209. 